\title{
PRIMEIRAS OBSERVAÇÕES SOBRE OS COLETIVOS DE TEATRO EM SÃO LUÍS: ASPECTOS DE UMA TERRITORIALIDADE EM PROCESSO DE PROFISSIONALIZAÇÃO
}

FIRST OBSERVATIONS ON THE THEATER COLLECTIVES IN SAO LUIS: ASPECTS OF TERRITORIALITY IN PROFESSIONALIZATION

\section{PRIMERAS OBSERVACIONES SOBRE EL TEATRO COLECTIVO EN SAO LUIS: ASPECTOS DE UNA TERRITORIALIDAD EN PROFESIONALIZACIÓN}

\section{Fernanda Areias de Oliveira}

Fernanda Areias de Oliveira

Professora do Departamento de Artes Cênicas, na Universidade

Federal do Maranhão (UFMA). Atua como docente no curso de licenciatura em Teatro e nos mestrados em Artes Cênicas e Cultura e Sociedade, da mesma universidade. Coordena o Grupo de Pesquisa Laboratório de Tecnologia Dramática (@labtecdrama). Esta pesquisa

é realizada com apoio da Fundação de Amparo à Pesquisa do Maranhão- FAPEMA e do Conselho Nacional de Pesquisa - CNPQ. E-mail: fernanda.areias@ufma.br 


\section{Resumo}

O artigo apresenta os primeiros dados ${ }^{1}$ referentes ao projeto de pesquisa "O vídeo na Cena Teatral", realizado pelo Grupo de Pesquisa Laboratório de tecnologias Dramáticas (LabTecDrama). Na primeira etapa desta pesquisa, discutem-se as relações entre o Estado e as políticas públicas para as Artes Cênicas no Maranhão, apresentando um breve diagnóstico sobre os coletivos em atuação da cidade de São Luís. Discutem-se, ainda, alguns aspectos referentes à Semana do Teatro do Maranhão, evento de teatro profissional com maior continuidade em território ludovicense.

Palavras-chave: políticas públicas de cultura, coletivos de teatro, São Luís.

\section{Abstract}

The article presents the first data regarding the research project "The Video in the Theatrical Scene", conducted by the Research Group Laboratory of Dramatic Technologies (LabTecDrama). The first stage of this research, discusses the state relations and public policies for the Performing Arts in Maranhão, presenting a brief diagnosis about the collectives in the city of São Luís. Some aspects related to the Maranhão Theater Week are also discussed, as the professional theater event with greater continuity in territory of São Luís.

Keywords: public policies of culture, theater collectives, São Luís.

\section{Resumen}

El artículo presenta los primeros datos sobre el proyecto de investigación "El video en la escena teatral", realizado por el Grupo de investigación Laboratorio de Tecnologías Dramáticas (LabTecDrama). En la primera etapa de esta investigación, discutimos las relaciones estatales y las políticas públicas para las Artes Escénicas en Maranhão, presentando un breve diagnóstico sobre los colectivos en la ciudad de São Luís. También, discutimos algunos aspectos con respecto a la Semana del Teatro de Maranhão, evento teatral profesional con mayor continuidad en territorio Ludovicense.

Palabras clave: políticas públicas de cultura, colectivos de teatro, São Luís.

\footnotetext{
1 LabTecDrama é um grupo de pesquisa pertencente ao Departamento de Artes Cênicas da Universidade Federal do Maranhão. Os dados apresentados compõem os planos de trabalho de iniciação científica das bolsistas Marilack Castro de Oliveira e Thaís Cristine Costa Noleto entre os anos de 2017 à 2019.
} 


\title{
COLETIVOS DE TEATRO EM SÃO LUÍS: (re)CONHECER PARA MAPEAR
}

O mapeamento de coletivos teatrais no Nordeste compreende uma das ações que reconhece a região como pertencente a uma estrutura autônoma no campo da produção teatral. Destacam-se iniciativas, como a publicação Cartografias do Teatro de Grupo do Nordeste (MA/PE/PI)2, organizada por Fernando Yamamoto. Em sua pesquisa, realizada entre os anos de $2009 \mathrm{e}$ 2012, menciona o número de quatro coletivos no Estado do Maranhão.

Nesse contexto, adicionam-se a este referencial documentos oficiais, a exemplo o Plano Estadual de Cultura do Maranhão, o qual aponta o quantitativo de 35 grupos de dança e teatro de rua, a partir de um instrumento denominado cadastro de identificação, sem mencionar as cidades cadastradas ou o nome dos respectivos coletivos. Ambas as publicações têm a ambição de um mapeamento sobre os fazedores de teatro no estado.

O empreendimento editorial, organizado por Yamamoto, apresenta ainda a ênfase sobre os modos de criação em teatro de grupo, destacando em seu mapeamento grupos que operacionalizariam em sua prática. Destarte:

\begin{abstract}
Teatro de grupo pode ser considerado um termo que se desdobra da expressão "grupo de teatro", no entanto, a única semelhança é a presença da unidade coletiva do pequeno grupo de trabalho. Com a inversão dos termos se produziu uma valorização do grupo como instância criativa. Este teatro seria definido pelo projeto grupal antes que pelas regras do mercado do espetáculo (YAMAMOTO, 2012, p. 10 , grifo nosso).
\end{abstract}

Partindo dessa concepção, o autor coloca no protagonismo de seu recorte o modo de criar em coletivo como motor de sua compreensão sobre o teatro de grupo, desvinculando de seu levantamento grupos que se reuniriam para produzir teatro juntos, mas sem corroborar coletivamente de uma horizontalidade nos processos de criação.

\footnotetext{
${ }^{2}$ Os grupos ludovicentes elencados por Yamamoto em sua publicação são: Cena Aberta, Pequena Cia, Santa Ignorância, Tapete e Xama Teatro.
} 
Sobre a perspectiva dos dados apontados no Plano Estadual de Cultura, não há qualquer indicação sobre a lógica de organização empregada ou da forma como foram catalogados trinta e cinco grupos de teatro e dança no estado. O mesmo documento chama a atenção para a fragilidade da produção teatral em um estado como o Maranhão. O contexto expõe uma produção em Artes Cênicas ainda intermitente e com pouca aderência às políticas públicas de fomento à cultura.

Em vista disso, menciona, em seu levantamento, que apenas treze projetos enviados por produções maranhenses, no ano de 2013, foram aprovados pela Comissão Nacional de Incentivo à Cultura. Em contrapartida, apresenta sua estratégia de mobilização para o incentivo à produção e à profissionalização da cultura local, destacando a criação do Sistema de Gestão e de Incentivo à Cultura (SEGIC).

(...) Lei № 8.319 de 12 de dezembro de 2005 que instituiu o Sistema de Gestão e de incentivo à Cultura - SEGIC; substituída pela Lei № 8.912 de 23 de dezembro de 2008 que alterou e consolidou o mesmo sistema. Com a criação do SEGIC, foram instituídos o Conselho Estadual de Cultura, (CONSEC); o Fundo de Desenvolvimento da Cultura Maranhense (FUNDECMA); a Comissão de Avaliação de Projetos (CAP); o Museu da Imagem e do Som (MIS), além das estruturas complementares como o Subsistema de Incentivo à Cultura (SINC); as Câmaras Técnicas (CTA'S) e a Secretaria Executiva (SESINC) (PLANO ESTADUAL DE CULTURA, 2014, p. 87, grifo nosso).

Dentro das estratégias apresentadas, destaca-se o Fundo de Desenvolvimento da Cultura Maranhense (FUNDECMA), que teria como objetivo: "incentivar projetos que visavam a exibição, a utilização ou a circulação pública de bens culturais nas áreas de Cênicas - teatro, dança, circo, ópera, mímica e congêneres" (Maranhão, 2010, p. 90). A referida iniciativa, a qual partiu do reconhecimento do Estado, em sua defasagem como fomentador de cultura, até o ano de 2019, contou apenas com a publicação do Edital Prêmio Literário 2018 e nenhum outro focado para as Artes Cênicas.

$\mathrm{Na}$ contramão do financiamento direto pelo governo estadual, em 18 de outubro de 2011, foi aprovada a Lei n. 9.437 - Lei Estadual de Incentivo 
à Cultura - que, aos moldes da Lei Rouanet ${ }^{3}$, incentiva a concessão de isenção fiscal para o contribuinte do Imposto sobre Circulação de Mercadorias e Prestação de Serviços de Transporte Interestadual e Intermunicipal e de Comunicação (ICMS) que financiar projeto cultural, incluindo a modalidade de espetáculos artísticos entre as possibilidades de financiamento. Assim, tanto a Lei Estadual de Incentivo à Cultura quanto o Fundo de Desenvolvimento da Cultura Maranhense (FUNDECMA) seriam as ações estaduais com maior potencial de financiamento de editais de fomento às Artes Cênicas.

O levantamento sobre coletivos teatrais partiria do cruzamento de possíveis recebedores de auxílio das fontes supracitadas. No entanto, um primeiro estudo apresentou o prognóstico de nenhum edital financiado pelo FUNDECMA voltado para as Artes Cênicas, e, em consulta da Secretaria Estadual de Cultura, não foi obtido acesso à lista de projetos aprovados para a captação de recursos desde a homologação da Lei Estadual, em 2011.

Portanto, partiu-se de um contexto em que a produção de espetáculos ocorre com escasso financiamento público para montagem ou manutenção de coletivos. Nesse sentido, em que ponto solucionar a necessidade de visualizar os coletivos produtores de teatro na cidade de São Luís? Optou-se por direcionar o recorte da pesquisa para o evento de teatro de maior continuidade no estado do Maranhão: A Semana do Teatro. Essa escolha ocorreu em decorrência de sua contínua permanência e abertura para a inscrição de coletivos de perfis variados.

Atualmente, organiza-se a 14 - Semana do Teatro sem que em nenhum ano após a sua criação tenha sido registrada a ausência do evento. Recortouse o período de 2006 a 2016, no intuito de se obter uma amostragem de dez anos. $O$ acesso aos dados foi feito por meio de catálogos cedidos pelo Centro de Memória do Teatro Arthur Azevedo, os quais serão discutidos neste escrito após tabulação.

\footnotetext{
${ }^{3}$ Lei federal criada no contexto Programa Nacional de Apoio à Cultura - PRONAC, na década de noventa. Prevê a aplicação de impostas para pessoas físicas e jurídicas, em ações de cunho cultural e artístico.
} 


\section{A SEMANA DO TEATRO DO MARANHÃO}

A Semana do Teatro do Maranhão é uma mostra de teatro não competitiva ${ }^{4}$, realizada desde o ano de 2006, sob a organização do Teatro Arthur Azevedo, o qual constitui um dos equipamentos culturais gerido pela Secretaria de Cultura do Estado do Maranhão, financiadora do evento 5 . A sua inscrição é gratuita, sendo permitida a participação de grupos de todos os estados do Brasil; destacando-se, em seus editais de chamamento, o incentivo ou a seleção específica de coletivos maranhenses.

Em algumas edições, foi incentivada a participação de grupos de cidades do interior do estado, como também a circulação de alguns selecionados em cidades para além da capital São Luís. No que se refere à documentação, não é constante a exigência no ato de inscrição; cabendo qualquer documento que comprove registro profissional dos artistas ou o Cadastro Nacional da Pessoa Jurídica (CNPJ) próprio das cias selecionadas. Assim, corrobora-se a possibilidade de inscrição de coletivos das mais diferentes etapas de profissionalização no evento.

No levantamento dos dados para esta pesquisa, encontrou-se uma variação significativa no quantitativo de apresentações por edição. O número apresentado na tabela abaixo se refere às múltiplas modalidades cênicas, contabilizando: teatro adulto, teatro para crianças, circo, teatro de rua e performance.

\footnotetext{
${ }^{4}$ Nas mais recentes edições do evento, foi instaurada a competição mediante a premiação de categorias, tais como: melhor ator/atriz, espetáculo, luz e etc.

${ }^{5}$ É preciso destacar uma mudança significativa no folheto da edição de 2016.0 referido material de divulgação descreve o evento como uma produção do Teatro Arthur Azevedo, com patrocínio do Grupo Equatorial Energia, empresa de energia elétrica do Maranhão, por meio da Lei Estadual de Incentivo à Cultura. Descaracterizando, assim, o processo de apoio direto via orçamento da Secretaria Estadual de Cultura; inserindo a Semana do Teatro no mesmo processo de arrecadação de patrocínio via isenção de ICMS.
} 
Tabela 1: Número de apresentações por edição na Semana do Teatro

\begin{tabular}{|c|c|}
\hline ANO/EDIÇÃO & No DE APRESENTAÇÕES \\
\hline $2006 / 1^{\text {a }}$ edição & 18 \\
\hline $2007 / 2^{\text {a }}$ edição & 21 \\
\hline $2008 / 3^{\text {a }}$ edição & 28 \\
\hline $2009 / 4^{\text {a }}$ edição & 27 \\
\hline $2010 / 5^{\text {a }}$ edição & 38 \\
\hline $2011 / 6^{\text {a }}$ edição & 30 \\
\hline $2012 / 7^{\text {a }}$ edição & 50 \\
\hline $2013 / 8^{\text {a }}$ edição & 36 \\
\hline $2014 / 9^{\text {a }}$ edição & 25 \\
\hline $2015 / 10^{\text {a }}$ edição & 30 \\
\hline $2016 / 11^{\text {a }}$ edição & 21 \\
\hline
\end{tabular}

Fonte: Informações retiradas dos Catálogos das Semanas do Teatro

Verificou-se que não há nenhum quantitativo mínimo ou máximo a ser respeitado, sendo esse número ${ }^{6}$ flexibilizado de acordo com o orçamento e as escolhas da comissão organizadora. No que tange ao número de grupos maranhenses que participaram nesse evento, o levantamento desta pesquisa apresentou, inicialmente, um número de setenta e sete coletivos. A quantidade expressiva deve ser também considerada dentro dos contextos de produção local e da ausência de editais de fomento às Artes Cênicas. Assim, a prática de montagens e a reunião de artistas com o intuito de efetivação de uma única participação do evento representam uma incidência significativa.

No entanto, tal quantitativo não será considerado na leitura sobre a investigação de coletivos de teatro da cidade de São Luís. Quanto às linguagens apresentadas, notou-se uma variedade relevante de formas artísticas, em que o espetáculo adulto representa a categoria mais incidente.

\footnotetext{
${ }^{6} \mathrm{~A} 14$ a Semana do Teatro apresentou, em seu edital, a indicação de seleção e 12 espetáculos. Desse quantitativo, 9 deveriam ser produções do Maranhão. Reconhece-se uma queda expressiva na contratação de espetáculos pelo evento.
} 
Gráfico 1: Linguagens cênicas apresentadas nos dez anos de evento. Fonte: Encartes de programação da Semana do Teatro no Maranhão concedidos pelo Teatro Arthur Azevedo (2018).

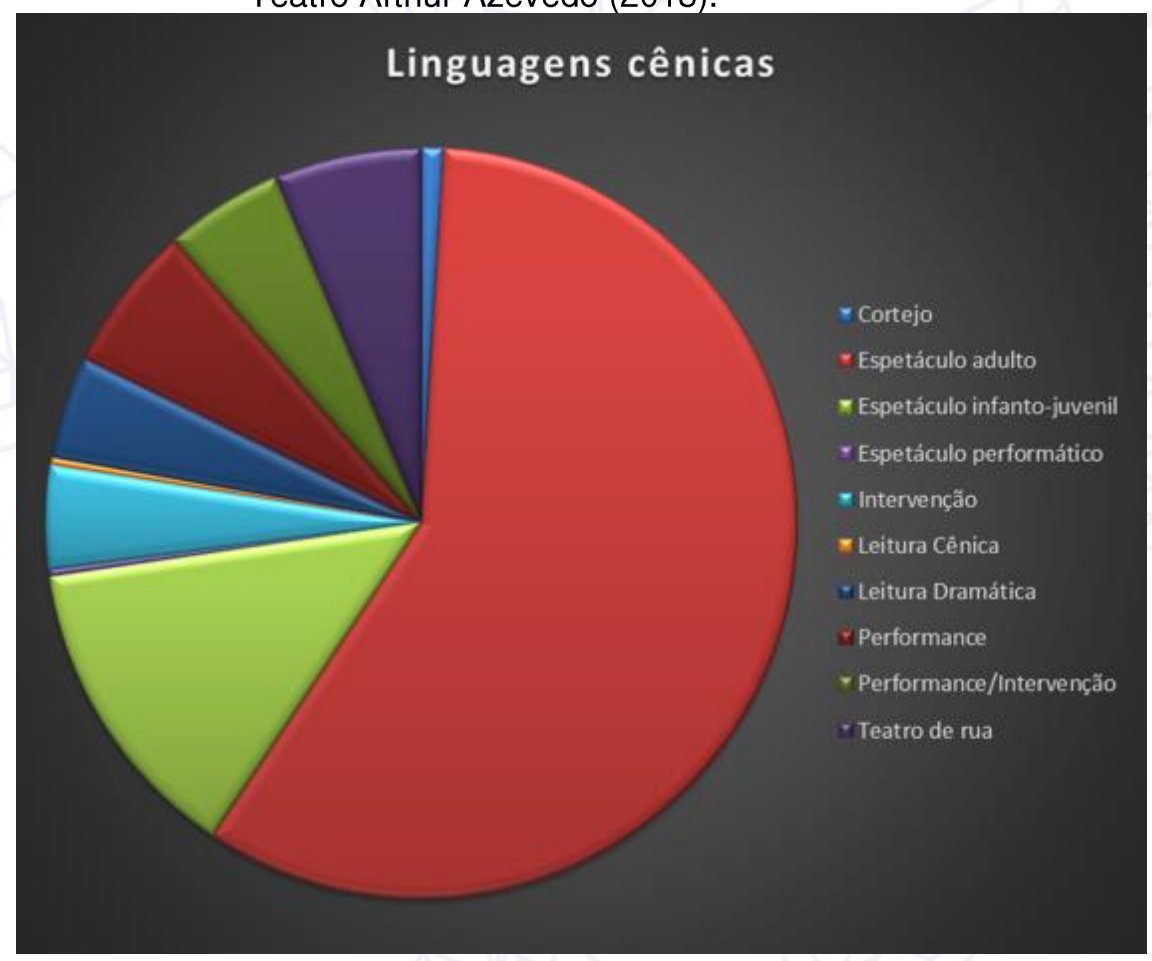

Com o intuito de ser um espaço de representação do teatro, realizado em todo o Estado do Maranhão, há uma significativa decalagem na quantidade de apresentações dos grupos da capital e do interior maranhense.

Gráfico 2: Cidades maranhenses representadas nas edições do evento. Fonte: Encartes de programação da Semana do Teatro no Maranhão concedidos pelo Teatro Arthur Azevedo (2018).

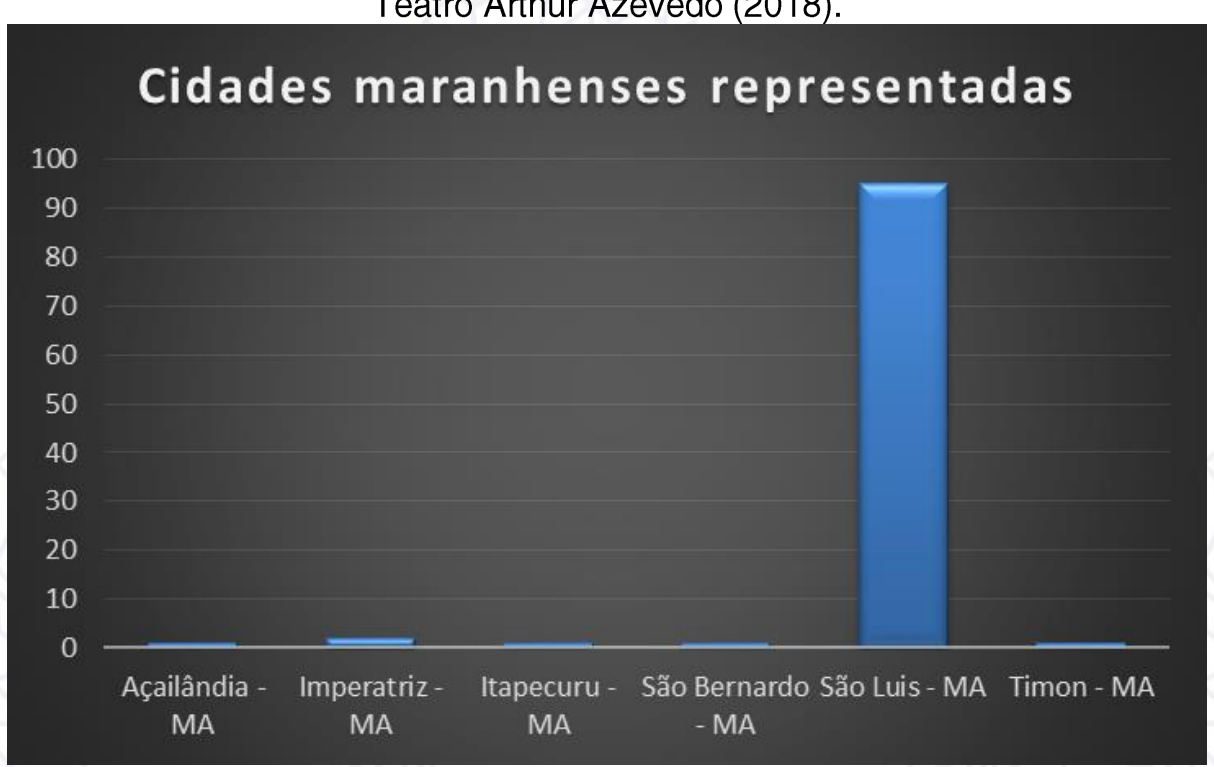




\title{
COLETIVOS LUDOVICENTES: PERFIS E AÇÕES
}

Reconhece-se como um dos pilares de entendimento de coletivos de teatro um recorte analítico vinculado à reunião de atores sociais implicados em produzir teatro; destarte, foram desconsideradas a obrigatoriedade do registro como empresa e a realização contínua de temporadas. A experiência nos modos de produção na cidade de São Luís permite identificar particularidades que não encontram ecos em outras capitais nordestinas, a saber: ausência de editais de fomento direcionados para artes cênicas ${ }^{7}$, a parca frequência de temporadas teatrais e a irregularidade na produção de espetáculos dos coletivos de teatro ${ }^{8}$. Na ocasião, é preciso diferenciar que o olhar não comunga com a tríplice apresentada por Trotta para a seleção dos coletivos apresentados nesta pesquisa:

\begin{abstract}
Apesar da diversidade infinita em termos de organização e estética, boa parte destes grupos aponta para um projeto artístico composto de três pilares: a criação que conjuga texto e cena na sala de ensaio, a presença do diretor como eixo artístico e organizativo, a continuidade da equipe. Os três elementos - grupo, processo e espetáculo - estão historicamente ligados à origem do teatro como arte autônoma, encarregada de encontrar seus próprios materiais, sua própria visão de mundo, seu modo específico de formação (TROTTA, 2006, p. 115, grifo nosso).
\end{abstract}

Os coletivos estudados participam de processos diversos em seus modos de criação, pertencendo, em alguns casos, a noção de teatro de grupo apresentada pela autora; enquanto, em outros casos, situam-se em distintas categorias de produção teatral, algumas mais comerciais ou ainda

\footnotetext{
${ }^{7}$ Para exemplificar, o estado do Ceará, por intermédio de sua Secretaria Estadual de Cultura, nos últimos anos, lançou os seguintes editais: Ocupação Artística do Theatro José de Alencar 2019, Edital de Credenciamento Artista, Presente! 2019, XII Edital Ceará de Incentivo às Artes e Edital de Chamada Pública para Realização do Programa de Formação em Artes Cênicas em Macrorregiões Culturais do Ceará.

${ }^{8}$ Até a data de envio deste artigo, os teatros públicos em São Luís não oferecem parcerias institucionalizadas com os artistas locais, como editais de ocupação ou residência criação, por exemplo. Alguns grupos desenvolveram a estratégia de se apresentarem em espaços próprios, podendo-se verificar tal tendência em grupos como: Grita, Laborarte, Xama Teatro e Pequena Cia.
} 
comunitárias. No entanto, comungam de relativa permanência ${ }^{9}$, continuidade das atividades e participação em mais de uma edição na Semana do Teatro.

Isto posto, o recorte do estudo busca uma amplitude na tentativa de dar visibilidade aos diversos modos de produzir teatro na cidade de São Luís, sem abortar nesse processo qualquer proposição estética vinculada aos fazedores de teatro identificados nesta pesquisa. Assim, foram excluídos do levantamento grupos nos quais o responsável identifica, na entrevista, a ausência de interesse na continuidade de membros, optando pela sazonalidade de convidados em seus processos, ou ainda, grupos formados por alunos de cursos livres de teatro, pertencentes a escolas do ensino fundamental e médio regular.

Ao longo das etapas de pesquisa desenvolvidas pelo Laboratório de Tecnologias Dramáticas (LabTecDrama), reconheceu-se um total de vinte e oito coletivos que, segundo as pesquisadoras, estão em atividade. A perspectiva adotada por esta pesquisa entende que atividades relacionadas ao teatro, mesmo que não diretamente vinculadas à montagem de espetáculos, deveriam ser contabilizadas como ações de teatro desses coletivos. Logo, contribuiu para a tomada de posição a compreensão de que se trata de um campo com pouca autonomização.

Pode-se medir o grau de autonomia de um campo de produção erudita com base no poder que dispõe para definir as normas de produção, os critérios de avaliação de seus produtos e, portanto, para retraduzir e reinterpretar todas as determinações externas de acordo com os princípios próprios de funcionamento. Em outros termos, quanto mais o campo estiver em condições de funcionar como arena fechada de uma concorrência pela legitimidade cultural, ou seja, pela consagração propriamente cultural e pelo poder propriamente cultural de concedê-la, tanto mais os princípios segundo os quais se realizam as demarcações internas e aparecem como irredutíveis a todos os princípios externos de divisão, por exemplo os fatores de diferenciação econômica, social ou política, como a origem familiar, a fortuna, o poder (no caso de um poder capaz de exercer sua ação diretamente sobre o campo), bem como tomadas de posição política (BOURDIEU, 2007, p. 106, grifo nosso).

\footnotetext{
${ }^{9}$ Após análise dos dados, verificou-se que apenas $28 \%$ dos coletivos elencados por esta pesquisa não tiveram sua criação nos anos 2000.
} 
O entendimento da ausência de autonomização do campo teatral, em São Luís, encaminha para o reconhecimento de ações associadas a vínculos na transversalidade da produção de espetáculos; uma vez que os agentes entrevistados ${ }^{10}$ apontam, em suas atividades atuais, práticas nos eixos de produção associados a: oferta de cursos formativos, publicação de dramaturgias, atividades de contação de histórias em eventos, entre outros. As atividades podem ser melhor visualizadas na tabela abaixo:

\begin{tabular}{|c|c|c|c|}
\hline & GRUPO & FUNDAÇÃO & ATIVIDADES \\
\hline 1 & $\begin{array}{c}\text { ABLUIR } \\
\text { PRODUÇÕES } \\
\text { ARTÍSTICAS }\end{array}$ & 2001 & $\begin{array}{l}\text { Produção de teatro de e cinema } \\
\text { em Portugal. }\end{array}$ \\
\hline 2 & $\begin{array}{l}\text { CIA CHEGANÇA } \\
\text { CIRCO TEATRO }\end{array}$ & 2007 & $\begin{array}{c}\text { Projetos de contação de } \\
\text { histórias. }\end{array}$ \\
\hline 3 & $\begin{array}{l}\text { CIA DO } \\
\text { IMAGINÁRIO }\end{array}$ & 2009 & $\begin{array}{l}\text { Projetos de performance e } \\
\text { contação de histórias, com } \\
\text { ênfase na infância. }\end{array}$ \\
\hline 4 & CIA MIRAMUNDO & 2011 & $\begin{array}{c}\text { Produção espetáculos teatrais } \\
\text { para rua e palco. }\end{array}$ \\
\hline 5 & $\begin{array}{l}\text { CIA NHÁ } \\
\text { CABOCA }\end{array}$ & 2014 & $\begin{array}{c}\text { Produção de espetáculos } \\
\text { voltados para a identidade de } \\
\text { gênero, negritude e ancestrais da } \\
\text { cultura popular maranhense. }\end{array}$ \\
\hline 6 & $\begin{array}{l}\text { COMPANHIA } \\
\text { ARTÍFICE-MOR }\end{array}$ & 2015 & $\begin{array}{l}\text { Produção de espetáculo e } \\
\text { capacitação de teatro em } \\
\text { comunidades. }\end{array}$ \\
\hline 7 & $\begin{array}{l}\text { CASA DO SOL } \\
\text { COMPANHIA DE } \\
\text { ARTES }\end{array}$ & 2014 & $\begin{array}{l}\text { Produção de espetáculo e } \\
\text { organização de treinamentos } \\
\text { físico e energético. }\end{array}$ \\
\hline 8 & $\begin{array}{l}\text { COMPANHIA } \\
\text { DIRETO DA } \\
\text { FONTE }\end{array}$ & 2011 & Produção de espetáculos. \\
\hline 9 & COTEATRO & 1998 & $\begin{array}{c}\text { Produção de espetáculo e } \\
\text { oficinas. }\end{array}$ \\
\hline 10 & $\begin{array}{l}\text { DRAO TEATRO } \\
\text { DA } \\
\text { (IN)CONSTÂNCIA }\end{array}$ & 2009 & $\begin{array}{l}\text { Publicação de literatura e suporte } \\
\text { na produção de outros grupos. }\end{array}$ \\
\hline 11 & $\begin{array}{l}\text { GRUPO DE } \\
\text { PESQUISA } \\
\text { TEATRAL CENA } \\
\text { ABERTA }\end{array}$ & 2004 & Produção de espetáculos. \\
\hline 12 & $\begin{array}{l}\text { GRUPO DE } \\
\text { TEATRO } \\
\text { IMPROVISO }\end{array}$ & 1995 & $\begin{array}{l}\text { O grupo trabalha com teatro } \\
\text { empresarial, produção de }\end{array}$ \\
\hline
\end{tabular}

${ }^{10} \mathrm{~A}$ etapa de entrevistas ainda está em andamento. Foi feito um primeiro contato com todos os coletivos para a verificação de suas atividades atuais. Em alguns casos, os dados apresentados são provenientes de divulgações fornecidas pelos próprios artistas, tais como: sites do coletivo e perfis em redes sociais. 


\begin{tabular}{|c|c|c|c|}
\hline & & & $\begin{array}{c}\text { espetáculos e eventos ligados ao } \\
\text { teatro e similares. }\end{array}$ \\
\hline 13 & $\begin{array}{l}\text { GRUPO GRITA } \\
\text { (GRUPO } \\
\text { INDEPENDENTE } \\
\text { DE TEATRO } \\
\text { AMADOR) } \\
\end{array}$ & 1975 & $\begin{array}{c}\text { Produção de espetáculos. O } \\
\text { grupo desenvolve um trabalho de } \\
\text { teatro na comunidade há } 40 \\
\text { anos, no bairro Anjo da Guarda, } \\
\text { em São Luís (MA). }\end{array}$ \\
\hline 14 & $\begin{array}{l}\text { GRUPO PÉ DE } \\
\text { FULÔ TEATRO E } \\
\text { BONECOS }\end{array}$ & 2006 & $\begin{array}{l}\text { Produção de espetáculos } \\
\text { infantis. }\end{array}$ \\
\hline 15 & $\begin{array}{c}\text { GRUPO } \\
\text { TEATRODANÇA }\end{array}$ & 1985 & $\begin{array}{c}\text { Produção de espetáculos, com } \\
\text { referenciais teóricos e práticas } \\
\text { sensoriais para a construção de } \\
\text { corporeidades contemporâneas } \\
\text { elaboradas a partir de matrizes } \\
\text { das culturas tradicionais } \\
\text { maranhenses. } \\
\end{array}$ \\
\hline 16 & $\begin{array}{c}\text { GRUPO } \\
\text { UNIVERSITÁRIO } \\
\text { DE TEATRO - } \\
\text { GUT } \\
\end{array}$ & 1996 & $\begin{array}{l}\text { Produção de espetáculos. } \\
\text { Realiza montagens a partir de } \\
\text { textos clássicos. }\end{array}$ \\
\hline 17 & $\begin{array}{c}\text { HU! HU! HU! } \\
\text { CIRCO TEATRO }\end{array}$ & 2012 & $\begin{array}{l}\text { Produção de espetáculos } \\
\text { voltados à técnica circense. }\end{array}$ \\
\hline 18 & $\begin{array}{l}\text { LABORATÓRIO } \\
\text { DE } \\
\text { EXPRESSÕES } \\
\text { ARTÍSTICAS } \\
\text { LABORARTE } \\
\end{array}$ & 1973 & $\begin{array}{l}\text { Produção de espetáculos. O } \\
\text { grupo trabalha com várias } \\
\text { linguagens artísticas e possui } 46 \\
\text { anos de atividade em } 2019 .\end{array}$ \\
\hline 19 & $\begin{array}{l}\text { NÚCLEO DE } \\
\text { INVESTIGAÇÃO } \\
\text { TEATRAL } \\
\text { FÓSFORO }\end{array}$ & 2005 & $\begin{array}{l}\text { Produção de espetáculos. Após } \\
\text { as mudanças no nome, } \\
\text { atualmente o grupo se chama } \\
\text { Coletivo Teatro do Redentor. }\end{array}$ \\
\hline 20 & $\begin{array}{c}\text { NÚCLEO DE } \\
\text { PESQUISAS } \\
\text { TEATRAIS } \\
\text { RASCUNHO } \\
\end{array}$ & 2010 & $\begin{array}{c}\text { Produção de espetáculos e } \\
\text { mesas de discussão. Trabalha } \\
\text { sobre o recorte da cena teatral } \\
\text { contemporânea. }\end{array}$ \\
\hline 21 & $\begin{array}{c}\text { PEQUENA } \\
\text { COMPANHIA DE } \\
\text { TEATRO }\end{array}$ & 2005 & $\begin{array}{l}\text { Produção de espetáculos. } \\
\text { Realiza circulação de } \\
\text { espetáculos e oficinas. }\end{array}$ \\
\hline 22 & $\begin{array}{l}\text { PETIT MORT } \\
\text { TEATRO }\end{array}$ & 2010 & $\begin{array}{l}\text { Produção de espetáculos. } \\
\text { Realiza intercâmbio com outros } \\
\text { grupos e desenvolve projetos e } \\
\text { roteiros na área de rádio novela. }\end{array}$ \\
\hline 23 & $\begin{array}{c}\text { SANTA } \\
\text { IGNORÂNCIA } \\
\text { CIA DE ARTES }\end{array}$ & 1997 & $\begin{array}{l}\text { Produção de espetáculos. } \\
\text { Realiza circulação de } \\
\text { espetáculos e oficinas. }\end{array}$ \\
\hline 24 & $\begin{array}{l}\text { TAPETE } \\
\text { CRIAÇÕES } \\
\text { CÊNICAS }\end{array}$ & 2001 & $\begin{array}{c}\text { Produção de espetáculos. O } \\
\text { grupo trabalha com várias } \\
\text { linguagens. }\end{array}$ \\
\hline 25 & $\begin{array}{l}\text { TRAMANDO } \\
\text { TEATRO }\end{array}$ & 1998 & $\begin{array}{l}\text { No momento, o grupo trabalha } \\
\text { apenas com passeios/serenatas } \\
\text { e aluguel de fantasias. }\end{array}$ \\
\hline 26 & XAMA TEATRO & 2008 & $\begin{array}{l}\text { Produção de espetáculos. } \\
\text { Realiza circulação de } \\
\text { espetáculos, oficinas, projetos de } \\
\text { intervenção cênica e contação de } \\
\text { história. }\end{array}$ \\
\hline
\end{tabular}




\begin{tabular}{|c|c|c|c|}
\hline 27 & $\begin{array}{c}\text { BEMDITO } \\
\text { COLETIVO }\end{array}$ & 2009 & $\begin{array}{c}\text { Produção de espetáculos. } \\
\text { Trabalha com a cena teatral } \\
\text { contemporânea, com êfase em } \\
\text { performance e dança. }\end{array}$ \\
\hline 28 & $\begin{array}{c}\text { COLETIVO } \\
\text { DIBANDO }\end{array}$ & 2016 & $\begin{array}{c}\text { Produção de espetáculos. } \\
\text { Trabalha com a cena teatral } \\
\text { contemporânea, com ênfase em } \\
\text { performance e dança. }\end{array}$ \\
\hline
\end{tabular}

Fonte: Entrevistas recolhidas pelo grupo de pesquisa LabTecDrama entre os anos de

(2017-2019)

A tabela permite a visualização de um repertório heterogêneo de vinte e oito práticas teatrais, destacando-se a juventude de boa parte desses coletivos: vinte tem seu período de criação nos anos 2000 e apenas oito são representantes das décadas de setenta, oitenta e noventa.

Sublinha-se, ainda, nesse levantamento, a variedade no repertório de ações e linguagens cênicas acessadas pelos coletivos elencados. $\mathrm{Na}$ etapa atual da pesquisa, dedicar-se-á ao acesso qualitativo dessas fontes; verificando os processos de formação e de autoformação dos artistas implicados nessa comunidade, como também sua aderência a editais de fomento e circulação nacionais e privadas.

Identificou-se um contexto de profissionalização teatral ainda instável e que acionam recursos privados ou externos ao Estado do Maranhão para a manutenção de suas atividades. Outro dado que interessa investir está associado às redes de artistas cênicos que, mediante o primeiro estudo, apresentam uma junção de membros. Muitos artistas pertencem a mais de um coletivo ou ainda, eventualmente, participa(ra)m de múltiplos coletivos.

Considerando tais pressupostos, pretende-se apresentar algumas particularidades do contexto de produção de teatro na cidade de São LuísMA, indicando a necessidade de distinguir modos diversos de pensar e produzir teatro nacionalmente. A atenção às particularidades regionais pode agregar a pesquisa em Artes Cênicas, revendo modelos e noções que frequentemente tomam as regionalidades do eixo sudestino como referência, invisibilizando práticas de territórios ainda não mapeados em suas especificidades. 


\section{Referências bibliográficas}

BOURDIEU, Pierre. O mercado de bens simbólicos. In: A economia das trocas simbólicas. Introdução, organização e seleção Sergio Miceli. São Paulo: Perspectiva, 2005.

GOVERNO DO ESTADO DO MARANHÃO. Políticas de estado para a cultura: o direito a ter direito à cultura $2015-2025$. Acesso em: http://www.sectur.ma.gov.br/wp-content/uploads/2016/01/PLANO-ESTADUAL-DECULTURA-Livro.pdf TROTTA, Rosyane. (2006). Autoralidade, grupo e encenação. Sala Preta, 6, 155164.

YAMAMOTO, Fernando Minicuci. Cartografia do teatro de grupo do Nordeste, Natal (RN): Clowns de Shakespeare, 2012. 